\title{
CHEMICAL VAPOR DEPOSITION OF Ti-Si-N FILMS FOR DIFFUSION BARRIER APPLICATIONS
}

\author{
Paul Martin Smith, a) J. S. Custer, a) Ronald V. Jones, a) Andrew W. Maverick, b)

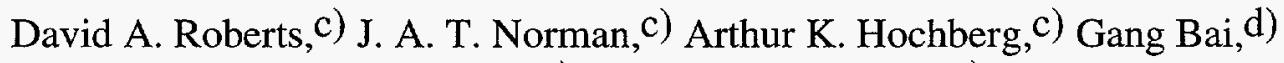 \\ Jason S. Reid,e) and Marc-A. Nicolet e)
}

a) Sandia National Laboratories, Albuquerque, NM 87185

b) Louisiana State University, Baton Rouge, LA 70803

c) Schumacher, Incorporated, Carlsbad, CA 92009

d) Intel Corporation, Santa Clara, CA 95052

e) California Institute of Technology, Pasadena, CA 91125

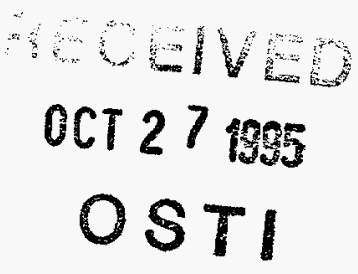

\section{Abstract}

Structurally disordered refractory ternary films such as titanium silicon nitride (Ti-Si-N) have potential as advanced diffusion barriers in future ULSI metallization schemes. We demonstrate chemical vapor deposition (CVD) of Ti-Si-N-containing films in a commercially available singlewafer CVD system using two different $\mathrm{Ti}$ precursors, $\mathrm{TiCl}_{4}$ and tetrakis(diethylamino)titanium (TDEAT). In particular, the TDEAT-based films can be grown conformally with low impurity content, and are promising candidates for advanced diffusion barrier applications.

\section{Introduction}

As critical dimensions for ULSI devices shrink ever smaller, new metallization technologies will be required. One necessity is a conformal, $10-20 \mathrm{~nm}$ thick diffusion barrier which is compatible with novel metals such as hot-sputtered Al, CVD Al, or Cu. Presently, sputtered TiN is the accepted material for diffusion barrier applications. The poor conformality of sputtering techniques has led to investigations of CVD TiN diffusion barriers, with two primary chemistries emerging as very promising. The first uses $\mathrm{TiCl}_{4}$ and $\mathrm{NH}_{3}$, and produces TiN films containing some $\mathrm{Cl}$, which is problematic because of the corrosion problems associated with $\mathrm{Cl}$ [1-3]. The second CVD chemistry uses metalorganic precursors such as tetrakis(dimethylamino)titanium (TDMAT) or tetrakis(diethylamino)titanium (TDEAT) in combination with $\mathrm{NH}_{3}$. It is reportedly difficult, however, to produce TiN films from these metalorganic precursors with low resistivity, good conformality, and low impurity levels [4,5]. Furthermore, since these TiN films are polycrystalline their barrier properties may be inadequate because of grain-boundary diffusion, particularly at thicknesses below $20 \mathrm{~nm}$.

Structurally disordered refractory ternary films such as $\mathrm{Ti}-\mathrm{Si}-\mathrm{N}$ have been shown to be promising candidates for $\approx 10 \mathrm{~nm}$ diffusion barrier applications by experiments on sputtered ternary films [6]. Sputtered Ti-Si-N films are thought to be composed of nanocrystals of TiN in a $\mathrm{Si}_{3} \mathrm{~N}_{4}$ matrix, giving a barrier with pre-stuffed grain boundaries[6-8]. Industrially relavent techniques for CVD of Ti containing ternaries, however, are relatively limited to date. Eizenberg et al. reported on the deposition of Ti-C-N from TDMAT and $\mathrm{NH}_{3}$ [5], indicating that the films were deposited conformally and were effective diffusion barriers. Raaijmakers et al. briefly reported on the deposition of Ti-Si-N from TDEAT, $\mathrm{SiH}_{4}$, and $\mathrm{NH}_{3}$ in 1994 [9], while Doan and Sandhu have patented a CVD technique using metalorganic precursors like TDEAT, along with $\mathrm{SiH}_{4}$ and $\mathrm{NH}_{3}$ for the deposition of films containing both $\mathrm{TiN}$ and $\mathrm{TiSi}_{2}$ [10]. $\mathrm{Li}$ et al. have also reported on a plasma enhanced CVD process for the deposition of Ti-Si-N at $560^{\circ} \mathrm{C}$ [11]. 


\section{DISCLAIMER}

This report was prepared as an account of work sponsored by an agency of the United States Government. Neither the United States Government nor any agency thereof, nor any of their employees, makes any warranty, express or implied, or assumes any legal liability or responsibility for the accuracy, completeness, or usefulness of any information, apparatus, product, or process disclosed, or represents that its use would not infringe privately owned rights. Reference herein to any specific commercial product, process, or service by trade name, trademark, manufacturer, or otherwise does not necessarily constitute or imply its endorsement, recommendation, or favoring by the United States Government or any agency thereof. The views and opinions of authors expressed herein do not necessarily state or reflect those of the United States Government or any agency thereof.

This report has been reproduced directly from the best available copy.

Available to DOE and DOE contractors from the Office of Scientific and Technical Information, 175 Oak Ridge Turnpike, Oak Ridge, TN 37831; prices available at (615) 576-8401.

Available to the public from the National Technical Information Service, U.S. Department of Commerce, 5285 Port Royal Road, Springfield, VA 22161; phone orders accepted at (703) 487-4650. 


\section{DISCLAIMER}

Portions of this document may be illegible electronic image products. Images are produced from the best available original document. 
In this letter we report on the development of two CVD processes for Ti-Si-N. The first uses $\mathrm{TiCl}_{4}, \mathrm{Si}_{2} \mathrm{H}_{6}$, and $\mathrm{NH}_{3}$ at temperatures of at least $500^{\circ} \mathrm{C}$. The relatively high deposition temperature, potential impact of chlorine in the films, and safety issues regarding $\mathrm{Si}_{2} \mathrm{H}_{6}$ make this film unattractive for commercial integrated circuit applications. The second process uses TDEAT, $\mathrm{SiH}_{4}$, and $\mathrm{NH}_{3}$ at 300 to $450^{\circ} \mathrm{C}$. The conformality of the deposited material and preliminary electrical measurements indicate these films are attractive diffusion barrier candidates for ULSI applications.

\section{Procedure}

The Ti-Si-N films were deposited on $150 \mathrm{~mm}$ Si wafers in a Materials Research Corporation Phoenix CVD system. The precursors are mixed in the showerhead, except where noted otherwise, and flow down over the wafer, which is mounted on a rotatable, heated susceptor. During all depositions the system pressure was maintained at 20 Torr and the wafers were rotated at $100 \mathrm{rpm}$. The deposition time was varied from 1 to 15 minutes, with 4 minutes being the typical deposition time. Thermal contact between the susceptor and wafer was enhanced by 10 Torr of $\mathrm{He}$ on the backside of the wafer. Depositions were performed on both thermal oxide and bulk $\mathrm{Si}$ wafers, as well as various test structures.

Film compositions were measured by Rutherford backscattering spectrometry (RBS) with $3.5 \mathrm{MeV} \mathrm{He}^{+}$and elastic recoil detection (ERD) using $28 \mathrm{MeV} \mathrm{Si}^{5+}$. The films were also characterized by mass gain and resistivity. Microstructure and gap fill were investigated with scanning electron microscopy (SEM). Film crystallinity was characterized by Read camera x-ray diffraction. Biased-thermal-stress testing of MOS capacitors was performed to test the effectiveness of the films as diffusion barriers for $\mathrm{Cu}$ metallization. The CVD films were compared against a sputtered TiN film produced by reactive DC magnetron sputtering of a Ti target in a $\mathrm{N}_{2} /$ Ar plasma in a system with a base pressure of $2 \times 10^{-7}$ Torr.

One chemistry investigated was $\mathrm{TiCl}_{4}, \mathrm{Si}_{2} \mathrm{H}_{6}$, and $\mathrm{NH}_{3}$ at a deposition temperature of $500^{\circ} \mathrm{C}$. Precursor flow rates were in the range of $0-50 \mathrm{sccm} \mathrm{TiCl}_{4}, 0-100 \mathrm{sccm} \mathrm{NH}_{3}$, and $0-250$ sccm $\mathrm{Si}_{2} \mathrm{H}_{6}$, with $5000 \mathrm{sccm} \mathrm{N} \mathrm{N}_{2}$ to establish the overall flow pattern in the reactor. The use of $\mathrm{Si}_{2} \mathrm{H}_{6}$ rather than $\mathrm{SiH}_{4}$ was required to obtain $\mathrm{Si}$ in the films at this temperature. The second chemistry used TDEAT, $\mathrm{SiH}_{4}$, and $\mathrm{NH}_{3}$ at deposition temperatures from $300-450^{\circ} \mathrm{C}$. It is surprising that the $\mathrm{SiH}_{4}$ reacted at these low temperatures; as shown in Table I, given the temperature required for $\mathrm{SiH}_{4}$ to react with $\mathrm{NH} 3$. This indicates that incorporation of $\mathrm{Si}$ in the films must somehow be promoted or catalyzed by the breakdown of TDEAT. The TDEAT was delivered from a heated bubbler (normally $80^{\circ} \mathrm{C}$ ) using $25-200 \mathrm{sccm}$ of $\mathrm{N}_{2}$ as carrier gas. The other precursor flow rates were $0-2000 \mathrm{sccm} \mathrm{NH}_{3}, 0-2000 \mathrm{sccm} \mathrm{N}_{2}$, and $0-500 \mathrm{sccm} \mathrm{SiH}_{4}$. Unfortunately, TDEAT reacts with the other precursors at the temperatures reached inside the showerhead, resulting in poor film quality (high concentrations of $\mathrm{C}$ and $\mathrm{O}$ ). The showerhead assembly was therefore modified to provide an individual injection port for TDEAT. While the films had very low impurity contents, the modified showerhead configuration produced nonuniform depositions that made determination of the film thicknesses and resistivities imprecise.

\section{Results and Discussion}

Figure 1 shows a Ti-Si-N ternary phase diagram [13] of the films grown using both the $\mathrm{TiCl}_{4}$ and TDEAT chemistries, including $\mathrm{TiCl}_{4}$-based films with $\mathrm{Cl} \leq 18$ at. $\%$ and $\mathrm{O} \leq 30$ at. $\%$ and TDEAT-based films with $\mathrm{C} \leq 3$ at. $\%$ and $\mathrm{O} \leq 3$ at. $\%$. The $\mathrm{TiCl}_{4}$-based film compositions generally follow a line from $\mathrm{TiSi}_{2}$ (grown without $\mathrm{NH}_{3}$ ) to $\mathrm{TiN}$ (grown without $\mathrm{Si}_{2} \mathrm{H}_{6}$ ), while the TDEAT- 
based films are clustered on the $\mathrm{N}$-rich side of the $\mathrm{Si}_{3} \mathrm{~N}_{4}$-TiN tie line (pure $\mathrm{Si}_{3} \mathrm{~N}_{4}$ cannot be deposited thermally at these temperatures). Raaijmakers et al. also found that TiN from TDEAT and $\mathrm{NH}_{3}$ is $\mathrm{N}$ rich [3]. These two chemistries allow access to a large region of the Ti-Si-N phase diagram, although the most promising barriers from previous sputtering studies are most likely along the $\mathrm{Si}_{3} \mathrm{~N}_{4}$-TiN tie line [7]. The only impurities found in the films by RBS or ERD were O, $\mathrm{H}$, and either $\mathrm{C}$ (in TDEAT-based films only) or $\mathrm{Cl}$ (in $\mathrm{TiCl}_{4}$-based films only). Impurity concentrations in the $\mathrm{TiCl}_{4}$-based films were typically $2-10$ at. $\% \mathrm{Cl}, 2-5$ at. $\% \mathrm{H}$, and up to 30 at. $\%$ $\mathrm{O}$ in some films. Oxygen was incorporated into these films upon exposure to air, as monitored by color change and mass gain of the wafers over time. Precursor mixes richer in $\mathrm{NH}_{3}$ resulted in airstable films with $\mathrm{O}$ contents below the detection limit of $\approx 1$ at. $\%$, although these conditions also limit the Si incorporation. TDEAT-based films contained 8-21 at.\% $\mathrm{H}, 1-30$ at. $\% \mathrm{C}$, and 1-30 at.\% $\mathrm{O}$ (again entering the film upon exposure to air) as impurities. Both the $\mathrm{C}$ and $\mathrm{O}$ contents could be reduced to below 3 at.\% by using sufficient $\mathrm{NH}_{3}$ flows, producing air-stable films.

Figure 2 shows cross-sectional SEMs of a $\mathrm{TiCl}_{4}$-based film and a TDEAT-based film deposited over an oxide step structure. The $\mathrm{TiCl}_{4}$-based film [Figure 2(a)] (deposited at $500^{\circ} \mathrm{C}$ with $20 \mathrm{sccm} \mathrm{TiCl} 4,500 \mathrm{sccm} \mathrm{Si} \mathrm{H}_{6}$, and $20 \mathrm{sccm} \mathrm{NH}_{3}$ ) exhibits a thin, conformal layer, covered by a layer that contains dendritic-like fiber bundles. Stopping the depositions before the fibrous material forms might produce films that are suitable for microelectronic applications, although it was not determined if these two regions have differing compositions. The very rough film cross section also makes it impossible to determine the resistivity. In contrast, the TDEAT-based film [Figure 2(b)] (deposited at $350^{\circ} \mathrm{C}$ with $100 \mathrm{sccm}$ TDEAT carrier gas $\left(\mathrm{N}_{2}\right), 100 \mathrm{sccm} \mathrm{SiH}_{4}$, and $1000 \mathrm{sccm} \mathrm{NH} 3$ ) grows conformally over the oxide steps at a rate of $10-20 \mathrm{~nm} /$ minute, with step coverage of better than $80 \%$. The vertical structure seen in the Ti-Si-N film is also observed on the original oxide steps and is a result of the etch used to define the structures. This conformality is similar to that observed previously for optimized TDEAT-based TiN films (85\% on similar structures) [9]. The resistivity of the TDEAT-based films as a function of Si content is shown in Figure 3. As the Si content rises, there is a strong increase in resistivity from $\approx 200 \mu \Omega$-cm for pure TiN films to over $1 \Omega$-cm at 25 at.\% Si. The deposited films may be in the free nitrogen regime, based on equilibrium thermodynamics, and weakly bonded $\mathrm{N}$ will tend to increase the resistivity of the films. From this data we believe that we can grow films with resistivities of $\leq 1000$ $\mu \Omega$-cm by lowering the $\mathrm{Si}$ and/or $\mathrm{N}$ content. The gap in the data from 0 at. $\% \mathrm{Si}$ to $\approx 12$ at. $\% \mathrm{Si}$ represents a $\mathrm{SiH}_{4}$ flow regime that was inaccessable with the mass flow controller used for this study.

\begin{tabular}{|c|c|c|}
\hline Precursors & Minimum Deposition Temperature & Deposited Material \\
\hline $\mathrm{TDEAT} / \mathrm{SiH}_{4} / \mathrm{NH}_{3}$ & $300^{\circ} \mathrm{C}$ & Ti-Si-N \\
\hline $\mathrm{TDEAT} \mathrm{NH}_{3}$ & $280^{\circ} \mathrm{C}[3]$ & TiN \\
\hline $\mathrm{TDEAT} / \mathrm{SiH}_{4}$ & $450^{\circ} \mathrm{C}[9]$ & Undetermined \\
\hline $\mathrm{SiH}_{4} / \mathrm{NH}_{3}$ & $700^{\circ} \mathrm{C}[12]$ & $\mathrm{Si}_{3} \mathrm{~N}_{4}$ \\
\hline
\end{tabular}

Table I. Precursor combinations for the TDEAT/SiH $4 / \mathrm{NH}_{3}$ deposition chemistry, minimum temperature required to obtain thermal CVD from these precursors, and constituents in the deposited material. 
Films produced using both the $\mathrm{TiCl}_{4}$ and TDEAT chemistries were investigated using $\mathrm{x}$-ray diffraction. TiN films from these precursors are polycrystalline, as has been observed previously [2,14]. In contrast, as-deposited Ti-Si-N films appear to be structurally disordered with a nanophase TiN component from the Read camera data. A $900^{\circ} \mathrm{C}$ anneal of the Ti-Si-N films for 1 hour produced material that contained polycrystalline TiN, by x-ray diffraction. We are reluctant to identify the as-deposited films as amorphous, since high-resolution TEM studies on sputtered Ti-Si-N have shown nanocrystalline TiN surrounded by an amorphous matrix (probably $\mathrm{Si}_{3} \mathrm{~N}_{4}$ ) when the X-ray data indicated an amorphous film [7,8]. The resistivity data in Figure 3 suggests that the CVD Ti-Si-N films have a similar microstructure, as increasing Si content (possibly as $\mathrm{Si}_{3} \mathrm{~N}_{4}$ ) rapidly increases the resistivity, as might happen if conduction were by hopping, or tunneling, between TiN nanocrystals. Certainly, the Ti-Si-N films do not contain large grains, allowing very thin films to be deposited uniformly, which is necessary for thin diffusion barrier applications.

To evaluate the potential of the TDEAT-based films as diffusion barriers, biased-thermalstress testing of MOS capacitors with $\mathrm{Cu}$ metallization over nominally $10 \mathrm{~nm}$ thick diffusion barriers was performed. The capacitors were stressed with $50 \mathrm{~V}$ at $200^{\circ} \mathrm{C}$, and the leakage current through the $100 \mathrm{~nm}$ oxide was monitored. When the diffusion barrier failed, $\mathrm{Cu}$ diffused rapidly through the oxide and caused oxide breakdown, leading to a rapid increase in the leakage current from approximately $1 \mathrm{nA} / \mathrm{cm}^{2}$ to approximately $10 \mathrm{~mA} / \mathrm{cm}^{2}$. Figure 4 shows failure data versus the inverse of the standard normal cumulative distribution for a sputtered TiN film, a TDEATbased film deposited at $350^{\circ} \mathrm{C}$ (with a composition of $\mathrm{Ti}_{0.31} \mathrm{Si}_{0.09} \mathrm{~N}_{0.47} \mathrm{C}_{0.01} \mathrm{H}_{0.12}$ ), and a TDEAT-based film deposited at $400^{\circ} \mathrm{C}\left(\mathrm{Ti}_{0.23} \mathrm{Si}_{0.14} \mathrm{~N}_{0.45} \mathrm{O}_{0.03} \mathrm{C}_{0.03} \mathrm{H}_{0.12}\right)$. The $400^{\circ} \mathrm{C}$ TDEAT-based film has a mean time to failure that is almost a factor of 100 larger than that measured for the sputtered TiN. These preliminary results indicate that the CVD Ti-Si-N films, especially the TDEAT-based films, may be suitable for diffusion barrier applications in ULSI devices.

\section{Conclusion}

Two CVD processes for structurally disordered refractory ternary Ti-Si-N have been developed in a commercially available cluster tool. The first process combines $\mathrm{TiCl}_{4}, \mathrm{NH}_{3}$, and $\mathrm{Si}_{2} \mathrm{H}_{6}$ at deposition temperatures of at least $500^{\circ} \mathrm{C}$, while the second uses TDEAT, $\mathrm{NH}_{3}$, and $\mathrm{SiH}_{4}$ at temperatures of $300-450^{\circ} \mathrm{C}$. Of these, the TDEAT process is more promising because of the precursors used, the lower deposition temperature required, and the conformal films produced. The two chemistries cover a wide range of the ternary phase diagram, including compositions near the $\mathrm{TiN}_{-} \mathrm{Si}_{3} \mathrm{~N}_{4}$ tie-line which are preferred for diffusion barriers [7]. Both chemistries result in TiSi-N films that appear to be structurally disordered by x-ray diffraction. The TDEAT-based films have deposition rates and conformality sufficient for thin barrier applications, and we believe that film resistivities of less than $1000 \mu \Omega$-cm can be produced. The initial biased-thermal-stress data indicate that the TDEAT-based films are better than sputtered TiN as diffusion barriers for $\mathrm{Cu}$ metallization. Although further work is needed to improve film uniformity, optimize the barrier properties, and address integration issues, we believe this work marks a major step forward in the development of advanced CVD diffusion barrier processes for future ULSI applications. 


\section{Acknowledgments}

The authors thank David Lilienfeld from the National Nanofabrication Facility, and Dave Fraser, Graham Alcott, and John Carruthers from Intel for many helpful discussions and support. Sandia National Laboratories is supported by the United States Department of Energy under Contract DE-AC04-94AL85000. Jason S. Reid gratefully acknowledges a fellowship from the Intel Foundation.

\section{References}

1. C. Arena, J. Faguet, R.F. Foster, J.T. Hillman, and D. Srinivas, in Advanced Metallization for ULSI Applications in 1993, edited by D. P. Favreau, Y. Shacham-Diamond, and Y. Horiike (Materials Research Society, Pittsburgh, PA, 1994) pp. 173-180.

2. J.T. Hillman, D. Srinivas, R.F. Foster, R.J. Graham, F. Shaapur, and M.R. McCartney, in Advanced Metallization for ULSI Applications in 1993, edited by D. P. Favreau, Y. ShachamDiamond, and Y. Horiike (Materials Research Society, Pittsburgh, PA, 1994) pp. 167-173.

3. I.J. Raaijmakers, R.N. Vrtis, G.S. Sandhu, J. Yang, E.K. Broadbent, D.A. Roberts, and A. Lagendijk, in Proc. 9th International IEEE VLSI Multilevel Interconnect Conference (IEEE, New York, 1992) pp. 260-266.

4. R.L. Jackson, E.J. McInerney, B. Roberts, J. Strupp, A Velaga, S. Patel, and L. Halliday, in Advanced Metallization for ULSI Applications in 1994, edited by R. Blumenthal and G. Janssen (Materials Research Society, Pittsburgh, PA, 1994) pp. 223-229.

5. M. Eizenberg, K. Littau, S. Ghanayem, A. Mak, Y. Maeda, M. Chang, and A.K. Sinha, Appl. Phys. Lett. 65 (19), 1994, pp. 2416-2418.

6. J.S. Reid, X. Sun, E. Kolawa, and M.-A. Nicolet, IEEE Elec. Dev. Lett. 15 (8), 1994, pp. 298300 .

7. J.S. Reid, Ph.D. Thesis, California Institute of Technology, May, 1995 (unpublished).

8. W. Posadowski, Thin Solid Films 162, 1988, pp. 111-117.

9. I.J. Raaijmakers, Thin Solid Films 247, 1994, pp. 85-93.

10. T.T. Doan and G.S. Sandhu, U.S. Patent No. 5,278,100 (11 January 1994).

11. Li Shizhi, Shi Yulong, and Peng Hongrui, Plasma Chemistry and Plasma Processing 12 (3), 1992, pp. 287-297.

12. A.C. Adams, in VLSI Technology, edited by S.M. Sze,(McGraw-Hill, New York, NY, 1983) p. 119 .

13. Phase Diagrams of Ternary Boron Nitride and Silicon Nitride Systems, edited by P. Rogl and J.C. Schuster (ASM International, Materials Park, OH, 1992) pp. 198-202.

14. I.J. Raaijmakers, R.N. Vrtis, J. Yang, S. Ramaswami, A. Lagendijk, D. A. Roberts, and E.K. Broadbent, in Advanced Metallization and Processing for Semiconductro Devices and Circuits II, edited by A. Katz (Mat. Res. Soc. Symp. Proc. 260, Pittsburgh, PA, 1992) pp. 99-105. 


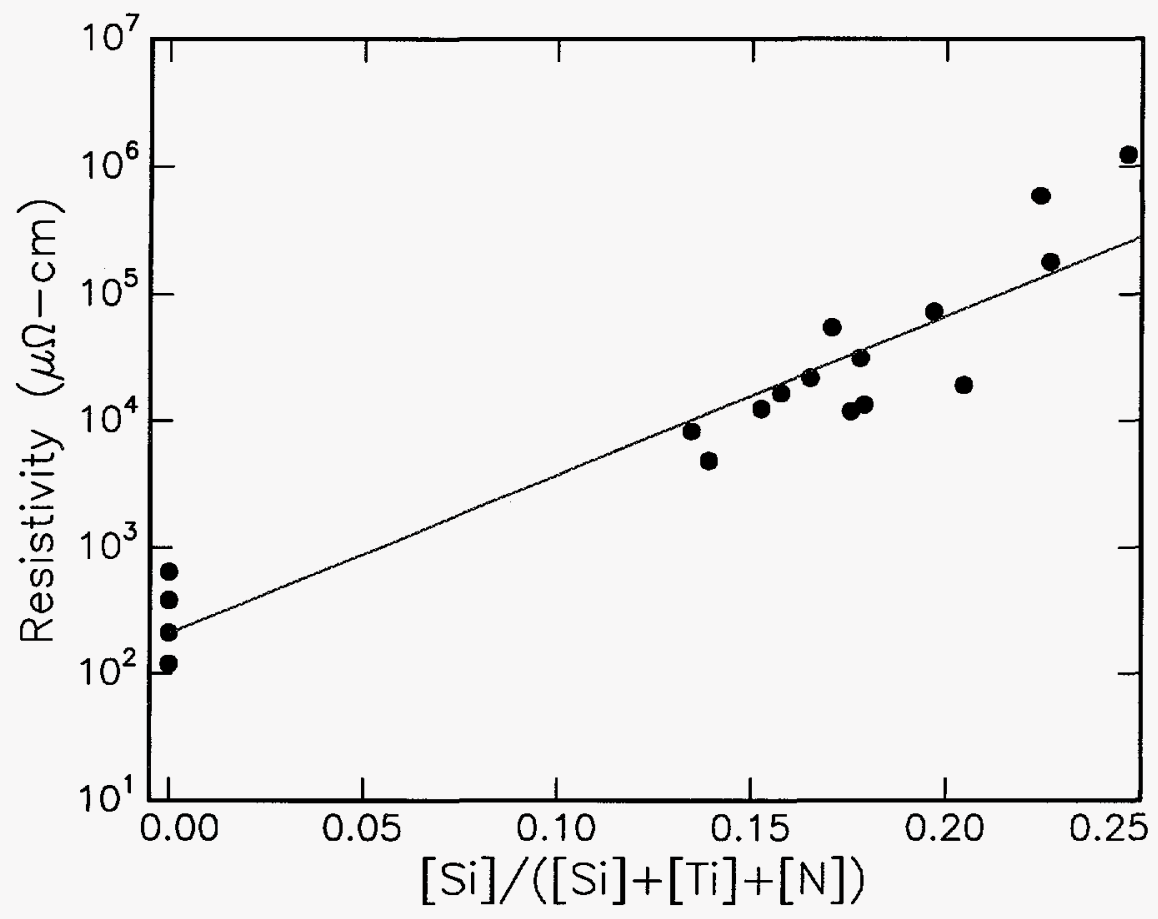

Figure 3. Resistivity of the TDEAT films as a function of Si content. There is a very strong increase in resistivity with $\mathrm{Si}$ content. The gap in the data from 0 to $\approx 12$ at.\% $\mathrm{Si}$ represents a $\mathrm{SiH}_{4}$ flow regime that could not be accessed by the mass flow controller used in this study.

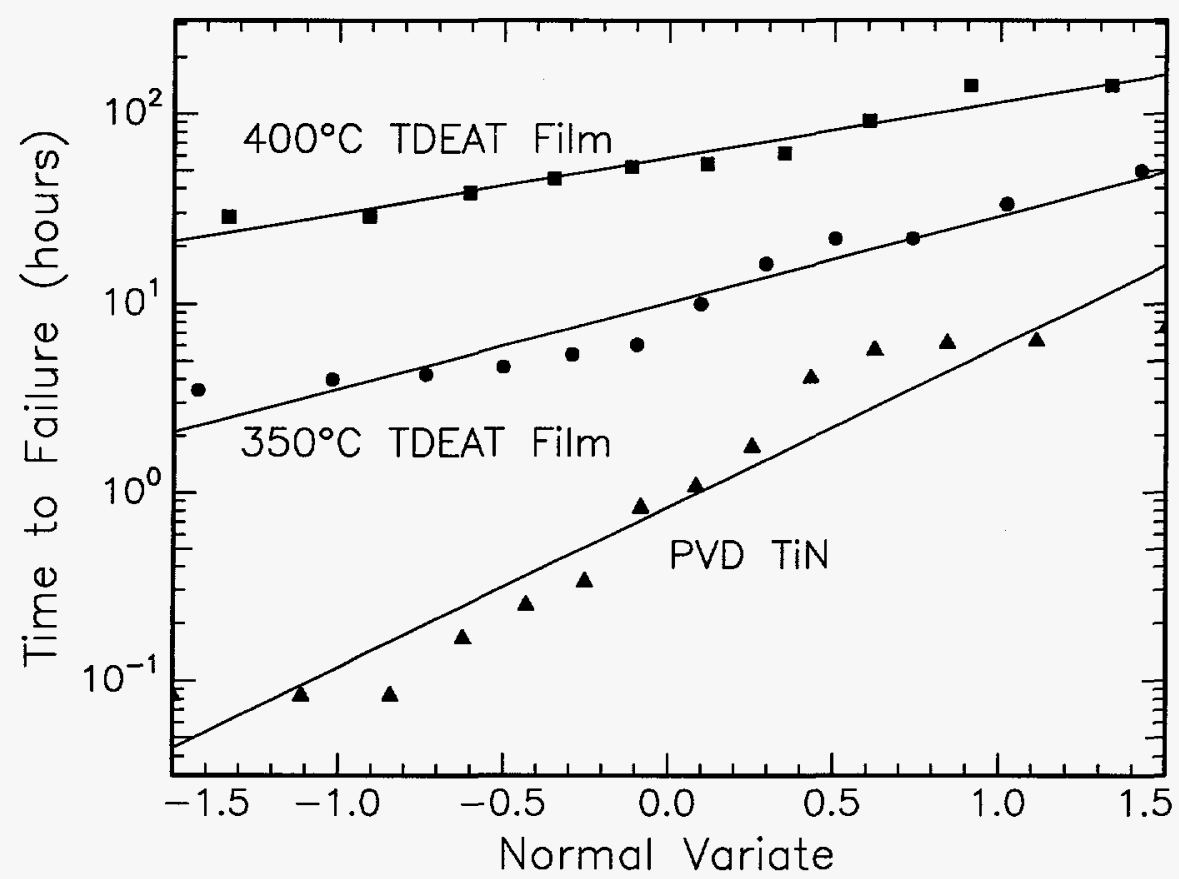

Figure 4. Biased-thermal-stress failure data for a sputtered TiN film and two TDEAT-based films, one deposited at $350^{\circ} \mathrm{C}$, and the other at $400^{\circ} \mathrm{C}$. The diffusion barrier thickness in all cases is nominally $10 \mathrm{~nm}$. The $400^{\circ} \mathrm{C}$ TDEAT-based film has a mean time to failure that is almost 2 orders of magnitude larger than that of the TiN film. 


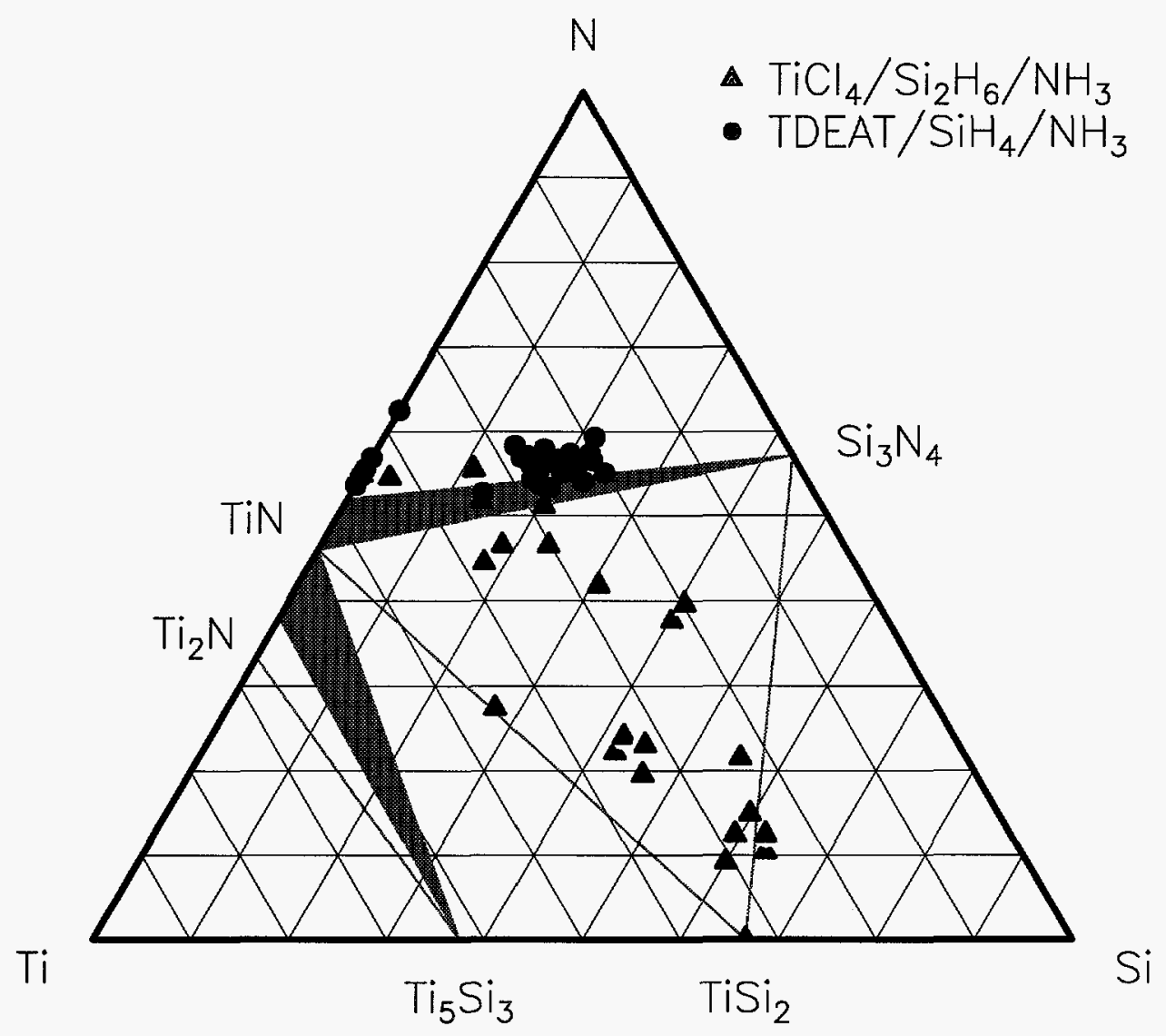

Figure 1. Ternary phase diagram of films produced with the TDEAT/SiH $4 / \mathrm{NH}_{3}$ and $\mathrm{TiCl}_{4} / \mathrm{Si}_{2} \mathrm{H}_{6} / \mathrm{NH}_{3} \mathrm{CVD}$ processes. The film stoichiometries are determined from the ratios of Ti:Si:N, ignoring any incorporated impurities. A wide stoichiometric range is accessed by use of the two chemistries reported here.

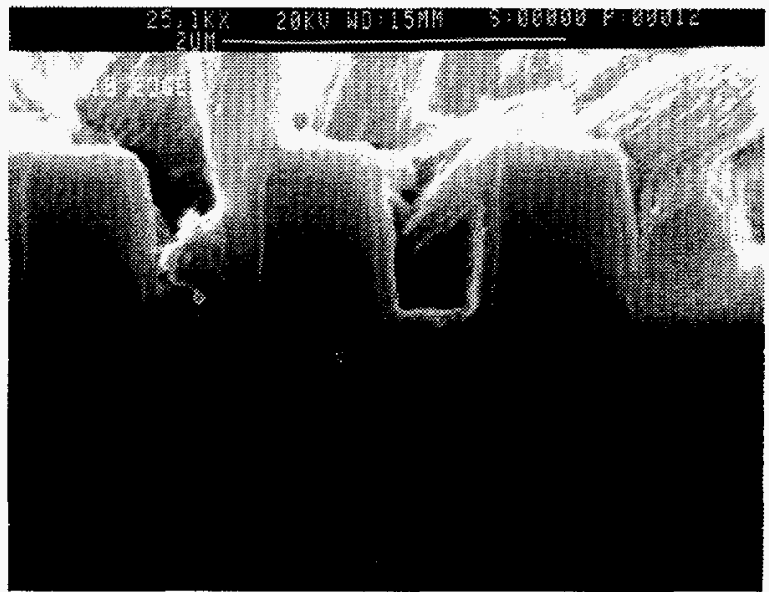

A

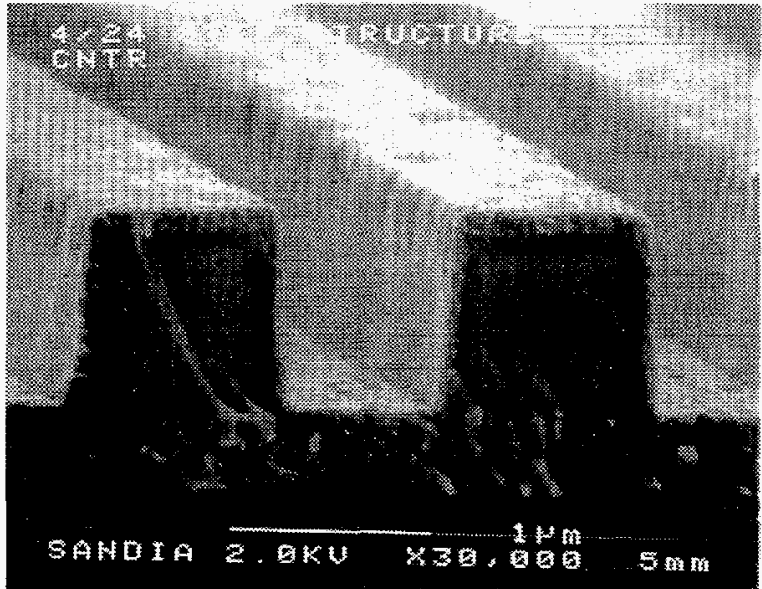

B

Figure 2. Cross-sectional SEMs of a $\mathrm{TiCl}_{4}$-based film (a) and a TDEAT-based film (b) deposited over an oxide step structure. The $\mathrm{TiCl}_{4}$-based film is composed of a thin, conformal layer and a layer made up of dendritic-like fiber bundles. It was not determined if the two growth regimes have the same composition. The TDEAT-based film is seen to be very conformal and to have step coverage of better than $80 \%$. 